\title{
Adherence to treatment guidelines in a university hospital: Exploration of facts and factors
}

\author{
Swarmita Afreen and Md. Sayedur Rahman
}

Department of Pharmacology, Bangabandhu Sheikh Mujib Medical University, Shahbag, Dhaka, Bangladesh.

\begin{tabular}{|c|c|}
\hline Article Info & \\
\hline Received: & 8 April 2014 \\
\hline Accepted: & 9 April 2014 \\
\hline Available Online: & 10 April 2014 \\
\hline DOI: 10.3329/bjp.v & 8537 \\
\hline $\begin{array}{l}\text { Cite this article: } \\
\text { Swarmita Afreen } \\
\text { Adherence to treat } \\
\text { a university hospi } \\
\text { facts and factors. } \\
\text { macol. 2014; } 9: 182-\end{array}$ & $\begin{array}{l}\text { Rahman MS. } \\
t \text { guidelines in } \\
\text { Exploration of } \\
\text { ladesh J Phar- }\end{array}$ \\
\hline
\end{tabular}

\begin{abstract}
The present study was conducted to evaluate the adherence to treatment guidelines in Bangabandhu Sheikh Mujib Medical University. The study assessed the awareness of prescribers, adherence to treatment guidelines and reasons for non-adherence. A questionnaire survey was conducted followed by a retrospective medical review and in-depth interview. The study revealed that $60.9 \%$ of key prescribers are aware of Treatment Guidelines. In pediatric patients, adherence was highest in neonatal sepsis $(71.7 \%)$ and lowest in bronchial asthma (3.3\%) and pneumonia (3.3\%). In adult patients, adherence was highest in rheumatoid arthritis (100\%) and lowest in bronchial asthma $(13.3 \%)$. Adherence was $29.5 \%$ and $52.7 \%$ in pediatric and adult patients respectively and difference was highly significant $(\mathrm{p}<0.001)$. The adherence was highest with International Guideline $(100 \%)$, followed by institutional Guideline $(71.7 \%)$ and National Guideline $(22.5 \%)$. There is significant variation in extent of adherence in different age group of patients, diseases and categories of guidelines.
\end{abstract}

\section{Introduction}

Prescribing has become extremely complex because of innovation of abundant medicines and consequently rationality of prescribing has been increasingly questioned. Commonly revealed irrationalities are polypharmacy, use of medicines not related to diagnosis, use of unnecessary expensive medicines, inappropriate use of antimicrobials, use of medicine with under dose and irrational self medication (Hogerzeil et al., 1995). International Network for the Rational Use of Drugs (INRUD) developed indicators which are considered as valid tool to get reliable representative data on pattern of medicine use (Hogerzeil et al., 1993). Series of studies were conducted in Bangladesh using those indicators, which generated evidences of varieties of irrationalities at different level of medical care and facilities (Rahman et al., 1998; Rahman et al., 1999; Rahman et al., 2001; Islam et al., 2007). Efforts have been increased to improve medicine use particularly in developing countries
(Arhinful et al., 1996). Different intervention strategies have been proven to improve medicine use, namely educational, managerial, financial and regulatory intervention (Quick et al., 1991; Islam et al., 2007; Chowdhury et al., 2008). The contemporary trend of clinical guidelines began in 1992 with a report of Institute of Medicine (IOM) that defined guidelines as 'systematically developed statements to assist practitioner and patient decisions about appropriate healthcare for specific clinical circumstances' (Field et al., 1990). The guidelines are regarded as a useful synthesis of current evidence or the consensus of a group of responsible and informed practitioners (Brown, 2002). Guidelines are developed institutionally, nationally or internationally (Brook, 1989; Grimshaw et al., 1994).

Introduction of Standard Treatment Guideline has resulted in varied outcomes in different countries and clinical conditions (Nabiswa et al., 1993; Naivaluevu, 1990; Kafuko et al., 1994). However, practice guidelines 
have become a popular tool to change the clinical practices and improve quality of health care (Grill et al., 2000). Medical institutes of developed countries follow either their national guideline or institutional guideline. In Bangladesh there are national guidelines for the treatment of diseases like, tuberculosis, malaria, kalaazar, asthma, diarrhea, filariasis and sexually transmitted diseases (STD), protein energy malnutrition etc (DGHS, 2012). Among few institutional guidelines published in Bangladesh, BSMMU antibiotic guideline (BSMMU, 2005) and Guideline for the treatment of genitourinary cancer (BSMMU, 2012) are mentionable.

The effectiveness or success of clinical guideline principally depends on the acceptance of guideline by the prescribers. The compliance of the prescribers to the Antibiotic Guideline of Bangabandhu Sheikh Mujib Medical University Hospital was evaluated, which had varied from one disease to another as well as one department to another (Siddika, 2012). Though the compliance to antibiotic guideline was evaluated, the compliance/adherence to other treatment guidelines has never been assessed in any institute of Bangladesh. The present study has been conducted to evaluate the adherence of treatment guidelines of the prescribers of BSMMU in treating common diseases in children and adult patients treated in the departments of Internal Medicine, Rheumatology, Pediatrics and Neonatology. The study also explored the awareness of the prescribers about clinical guidelines and the factors influencing adherence status.

\section{Materials and Methods}

This is an observational cross sectional type of study and the study was conducted in the departments of Internal Medicine, Rheumatology, Pediatrics and Neonatology under the supervision of the department of Pharmacology, Bangabandhu Sheikh Mujib Medical University (BSMMU). Initially a questionnaire survey was conducted among the key prescribers of the BSMMU hospital. The retrospective prescribing data was collected from the Record Room of the BSMMU. The In-depth interview was conducted among 10 key prescribers of the departments of Internal Medicine, Rheumatology, Pediatrics and Neonatology.

Total duration of the study was from January 2012 to June 2013. Ethical issues of this study was reviewed and approved by Institutional Review Board of Bangabandhu Sheikh Mujib Medical University.

In this study, total eight diseases were selected, four diseases of the adults treated in the departments of Internal Medicine and Rheumatology and four diseases of children and neonates treated in the departments of Pediatrics and Neonatology. Four diseases like bronchial asthma, COPD, kala-azar and rheumatoid arthritis were selected to be studied in adult. Four diseases like bronchiolitis, bronchial asthma, childhood pneumonia, and neonatal sepsis were selected to be studied in children and neonates.

Treatment records of individual cases containing clinical diagnosis of selected diseases were considered as sample and samples were collected by consecutive sampling method. Treatment sheet containing more than two diagnoses, documented as discharged on request, absconded and expired are excluded from this study. Sixty treatment sheets (WHO, 1993) of each disease (except kala-azar and bronchial asthma of children, in which case 23 and 30 treatment sheets respectively) was included and accordingly the sample size was 413 .

\section{Data collection}

Initially a questionnaire survey was conducted among the key prescribers (Chairman, Professor, Associate professor and Assistant professor) in all the departments of BSMMU hospital using a questionnaire that was a modified form of the previously developed one (Siddika, 2012). The purpose of the survey was to know about the preferred guidelines of the prescribers for common diseases they treat in their departments.

Then a retrospective study was conducted by evaluating the treatment sheets conserved in the record room. The included cases were reviewed to evaluate the adherence with the treatment guidelines as mentioned by the key prescribers.

Finally in-depth interview was conducted (Haque, 2009; Islam et al., 2007; Das and Rahman, 2010) with the prescribers in order to assess their perception regarding treatment guidelines and reasons for non-adherence or less adherence with the guidelines.

The trade name of the medicine commonly prescribed in the selected diseases was checked and memorized by the researcher using Bangladesh National Formulary (DDA, 2006) and the website of the Directorate General of Drug Administration, www.dgda.gov.bd.

Data collection started from the most recently registered in-patient records to gradually backward manner. The treatment records of the selected disease in the register were initially identified. Then the treatment sheets were reviewed for the inclusion and exclusion criteria to be included in the study. After inclusion, the treatment record of the selected disease was reviewed. Initially an ID was provided at top of the front page of the treatment sheet where confirmed clinical diagnosis and patient profile were mentioned.

The following information were documented in review form: serial number of the prescription, date of the prescription, name of medicines in generic name (whether prescribed as generic or in trade name), 
formulation of medicines (either tablet or capsule or injections or inhaler or syrup or suspension or suppository), dose of the medicines, frequency of therapy, duration of hospital stay, route of medicine administration and number of medicines per prescription.

The change of antimicrobial was evaluated to identify whether that was done on the basis of clinical findings or on laboratory findings (in follow up note). If that was based on laboratory findings, the prescription was considered adhered. In the prescription where the change was based on clinical findings, if the changed medicine was from the Guideline, the treatment was evaluated accordingly.

Finally, after inclusion of the cases, information regarding confirmed clinical diagnosis, patient profile, records of prescribing and detail information of medicine was documented in an audit form. The treatment provided for the mentioned diagnosis was only considered for the assessment. The remaining part of the prescription was not studied in this study.

\section{Assessment of the adherence}

Among the selected diseases common in adults, adherence was evaluated by matching with the National guideline (in case of bronchial asthma, COPD and kalaazar) and NICE guideline (in case of rheumatoid arthritis).

In case of selected disease of children and neonates, adherence was evaluated by matching the recommendation of National guideline (in case of bronchiolitis, bronchial asthma and childhood pneumonia) and consensus protocol of the key prescribers of the Department of Neonatology (in case neonatal sepsis).

Prescriptions of every disease were assessed for their adherence status by comparing them with the preferred guideline as mentioned by the key-prescribers treating that particular disease. The clinical decisions were considered correct, only the following pharmacological issues mentioned in the guideline were compared: Selection of medicine, dose of medicine, frequency of therapy and route of administration of medicine.

\section{Working principle of adherence assessment}

If any prescription contains selected medicine as mentioned in the treatment guideline plus medicine unmentioned in the guideline, that prescription was not considered as 'adherence' because this study was conducted only to explore pharmacological issues, not the clinical judgment.

In case of antibiotic, if the selection was according to guideline, only then it was considered as 'adherence' and further studied for dose, route and frequency. If any unmentioned antibiotic was prescribed, that was considered as 'non-adherence'. Guideline that has incomplete information about dose, route and frequency, recommendation of national formulary was considered.

Initially, the name of the prescribed medicine was compared with the preferred guideline, whether that is mentioned or not in the Guideline. If the medicine was not from the mentioned list, then the prescription was considered as 'non-adherence' and the remaining steps to study dose, route and frequency were not performed. If the medicine was selected from the mentioned list, then the remaining steps, i.e., whether the mentioned dose, route and frequency were according to the recommendations of the guideline or not, was evaluated. Afterwards, the prescription was scored in the following manner: For every correct criteria, the prescription received one point and if the total score of the prescription was four, they were labeled as complete adherence. If any medicine that is mentioned in the treatment guideline as discouraged to prescribe or some clinical criteria were mentioned as prerequisite, in that case if prerequisite were not met, it was considered as 'non-adherence'. Adherence status was evaluated by a spreadsheet developed in Microsoft Office Excel by providing preset formula.

\section{Analysis}

Appropriate statistical test (ANOVA, Z-test of proportion etc) was done in this study for drawing an effective conclusion. Statistical analysis was done with the help of online statistical analysis calculator and Microsoft Office Excel.

\section{Results}

The initial questionnaire survey revealed that among the key prescriber requested to participate, $36.5 \%$ $(46 / 126)$ participated in the survey. Of the participated prescriber, $60.9 \%(28 / 46)$ of the key prescribers of BSMMU hospital are aware of treatment guidelines.

Key prescribers from 39 departments have mentioned 73 diseases/clinical conditions treated in their departments, of which International Guidelines (33/73), National Guideline (4/73), institutional guideline $(12 / 73)$ and textbooks/journal/own experience (24/73) are followed as their guiding principles. Detail list of the preferred guidelines are available on request to the corresponding author.

Table I revealed that out of 210 treatment sheets of pediatric patients, 62 completely adhered to the treatment guidelines. The adherence was highest in case of neonatal sepsis $(43 / 60)$ and was lowest in case of bronchial asthma (1/30). It was found that out of 203 treatment sheets of the departments of Internal Medicine and Rheumatology, 107 completely adhered to the treatment guidelines. The adherence was highest in 


\begin{tabular}{|c|c|c|c|c|c|c|c|c|c|c|}
\hline \multicolumn{11}{|c|}{ Table I } \\
\hline \multicolumn{11}{|c|}{$\begin{array}{l}\text { Appropriateness of selection of medicine and the adherence status with guidelines in children and } \\
\text { adults treated in the corresponding departments }\end{array}$} \\
\hline \multirow{2}{*}{ Disease } & \multirow{2}{*}{$\begin{array}{l}\text { Num } \\
\text { ber of } \\
\text { cases }\end{array}$} & \multirow{2}{*}{$\begin{array}{l}\text { Medi- } \\
\text { cine } \\
\text { selection }\end{array}$} & \multicolumn{8}{|c|}{ Adhered } \\
\hline & & & $\begin{array}{l}\text { Dose, } \\
\text { route \& } \\
\text { frequen- } \\
\text { cy }\end{array}$ & $\begin{array}{l}\text { Com- } \\
\text { plete }\end{array}$ & $\begin{array}{l}\text { Dose } \\
\& \\
\text { route }\end{array}$ & $\begin{array}{c}\text { Dose \& } \\
\text { fre- } \\
\text { quency }\end{array}$ & $\begin{array}{c}\text { Route \& } \\
\text { fre- } \\
\text { quency }\end{array}$ & Dose & Route & $\begin{array}{c}\text { Fre- } \\
\text { quency }\end{array}$ \\
\hline \multicolumn{11}{|l|}{ Children } \\
\hline $\begin{array}{l}\text { Bronchial } \\
\text { asthma }\end{array}$ & 30 & $11 / 30$ & $1 / 11$ & $1 / 30$ & $2 / 11$ & $0 / 11$ & $7 / 11$ & $0 / 11$ & $1 / 11$ & $0 / 11$ \\
\hline Bronchiolitis & 60 & $57 / 60$ & $16 / 57$ & $16 / 60$ & $6 / 57$ & $0 / 57$ & $25 / 57$ & $0 / 57$ & $10 / 57$ & $0 / 57$ \\
\hline $\begin{array}{l}\text { Childhood } \\
\text { pneumonia }\end{array}$ & 60 & $31 / 60$ & $2 / 31$ & $2 / 60$ & $0 / 31$ & $0 / 31$ & $29 / 31$ & $0 / 31$ & $0 / 31$ & $0 / 31$ \\
\hline $\begin{array}{l}\text { Neonatal sep- } \\
\text { sis }\end{array}$ & 60 & $60 / 60$ & $43 / 60$ & $43 / 60$ & $0 / 60$ & $0 / 60$ & $16 / 60$ & $0 / 60$ & $1 / 60$ & $0 / 60$ \\
\hline Total & 210 & $159 / 210$ & $62 / 159$ & $62 / 210$ & $8 / 159$ & $0 / 159$ & $77 / 159$ & $0 / 159$ & $12 / 159$ & $0 / 159$ \\
\hline \multicolumn{11}{|l|}{ Adult } \\
\hline $\begin{array}{l}\text { Bronchial } \\
\text { asthma }\end{array}$ & 60 & $28 / 60$ & $8 / 28$ & $8 / 60$ & $11 / 28$ & $0 / 28$ & $7 / 28$ & $0 / 28$ & $2 / 28$ & $0 / 28$ \\
\hline COPD & 60 & $40 / 60$ & $19 / 40$ & $19 / 60$ & $12 / 40$ & $0 / 40$ & $6 / 40$ & $0 / 40$ & $3 / 40$ & $0 / 40$ \\
\hline Kala-azar & 23 & $23 / 23$ & $20 / 23$ & $20 / 23$ & $0 / 23$ & $0 / 23$ & $3 / 23$ & $0 / 23$ & $0 / 23$ & $0 / 23$ \\
\hline $\begin{array}{l}\text { Rheumatoid } \\
\text { arthritis }\end{array}$ & 60 & $60 / 60$ & $60 / 60$ & $60 / 60$ & $0 / 60$ & $0 / 60$ & $0 / 60$ & $0 / 60$ & $0 / 60$ & $0 / 60$ \\
\hline Total & 203 & $151 / 203$ & $107 / 151$ & $107 / 203$ & $23 / 151$ & $0 / 151$ & $16 / 151$ & $0 / 151$ & $5 / 151$ & $0 / 151$ \\
\hline
\end{tabular}

case of rheumatoid arthritis $(60 / 60)$ and was lowest in case of bronchial asthma (8/60).

Table II showed that proportion of total adhered prescription was $29.5 \%$ in children and neonates treated in the Departments of Pediatrics and Neonatology, which was $52.7 \%$ in adult treated in the Departments of Internal Medicine and Rheumatology. The difference between totally adhered prescriptions of children and adult patients treated in BSMMU hospital was highly significant $(\mathrm{p}<0.001)$.

The Table III showed that among the diseases treated in the Departments of Pediatrics and Neonatology, the mean score obtained was highest in case of neonatal sepsis $(3.7 \pm 0.5)$ and lowest in case of bronchial asthma $(3.0 \pm 0.5)$. Among the diseases treated in Departments of Internal Medicine and Rheumatology, the mean score obtained was highest in case of rheumatoid arthritis $(4.0 \pm 0.0)$ and lowest in case of bronchial asthma $(3.2 \pm 0.6)$. In Departments of Pediatrics and Neonatology, the F value was 23.5 and the difference between the patient of different diseases was highly significant $(\mathrm{p}<0.001)$. In Departments of Internal Medicine and Rheumatology, the F value was 33.0 and the difference between the patient of different diseases was highly significant $(\mathrm{p}<0.001)$.

When adherence was assessed in treated diseases with the corresponding preferred guideline of different categories, highest, i.e., $100 \%$ adherence was observed with International Guideline, followed by $71.7 \%$ with Institutional Guideline (Consensus Protocol) and 22.5\% with National Guideline.

From the In-depth interview, different managerial issues like improper distribution, communication gap between the management and prescribers as well as lack of persuasion from the administration were mentioned as reason of non-adherence. Some scientific issues also mentioned like faulty guideline development process, not up-to-date, too complicated to follow and difference in clinical scenario than that mentioned in the Guideline. Furthermore, some prescriber related aspects like inadequate motivation, reluctance of junior prescribers, time constraints and empirical preference to individual's experience were mentioned by the key prescriber as reason of non-adherence.

Proper distribution, dissemination and availability of the guidelines were suggested by the key prescriber as measure to improve adherence. They also advised to update the guideline regularly and to incorporate recent laboratory data into the guideline. Orientation and motivational programs were also mentioned by the key prescriber as measure to improve awareness as well as adherence. Finally, they suggested some stringent legal provision to enforce better adherence. 


\section{Table II}

Proportion of prescriptions that completely adhered with the preferred guidelines of the key prescribers

\begin{tabular}{|c|c|c|c|c|c|c|c|}
\hline \multirow[t]{2}{*}{ Department } & \multirow[t]{2}{*}{ Disease } & \multirow[t]{2}{*}{$\mathrm{n}$} & \multicolumn{2}{|c|}{ Complete adherence } & \multirow{2}{*}{$\begin{array}{l}\text { Total complete adherence } \\
\text { rate }(\%)\end{array}$} & \multirow[t]{2}{*}{$\mathrm{Z}$} & \multirow[t]{2}{*}{$\mathrm{p}$} \\
\hline & & & Number & Percent & & & \\
\hline \multirow{5}{*}{$\begin{array}{l}\text { Pediatrics and } \\
\text { Neonatology }\end{array}$} & Bronchial asthma & 30 & 1 & 3.3 & \multirow[t]{5}{*}{29.5} & \multirow[t]{10}{*}{0.97} & \multirow[t]{10}{*}{0.000} \\
\hline & Pneumonia & 60 & 2 & 3.3 & & & \\
\hline & Bronchiolitis & 60 & 16 & 26.7 & & & \\
\hline & Neonatal sepsis & 60 & 43 & 71.7 & & & \\
\hline & Total & 210 & 62 & 29.5 & & & \\
\hline \multirow{5}{*}{$\begin{array}{l}\text { Internal Medicine } \\
\text { and Rheumatolo- } \\
\text { gy }\end{array}$} & Bronchial asthma & 60 & 8 & 13.3 & \multirow[t]{5}{*}{52.7} & & \\
\hline & COPD & 60 & 19 & 31.7 & & & \\
\hline & Kala-azar & 23 & 20 & 87.0 & & & \\
\hline & Rheumatoid arthritis & 60 & 60 & 100 & & & \\
\hline & Total & 203 & 107 & 52.7 & & & \\
\hline
\end{tabular}

\section{Table III}

The adherence score regarding selection of medicine, dose, route and frequency of administration

\begin{tabular}{|c|c|c|c|c|c|c|c|c|c|}
\hline Pediatrics and Neonatology & Mean & SD & & & SS & $\mathrm{df}$ & MS & $\mathrm{F}$ & $\mathrm{P}$ \\
\hline Bronchial asthma & 3.0 & 0.4 & \multirow{4}{*}{$\begin{array}{l}\mathrm{A} \\
\mathrm{N} \\
\mathrm{O} \\
\mathrm{V} \\
\mathrm{A}\end{array}$} & Between & 17.4 & 3 & 5.8 & \multirow[t]{4}{*}{23.5} & \multirow[t]{4}{*}{0.000} \\
\hline Bronchiolitis & 3.1 & 0.7 & & Within & 50.7 & 206 & 0.2 & & \\
\hline Pneumonia & 3.1 & 0.2 & & Total & 68.1 & 209 & & & \\
\hline Neonatal sepsis & 3.7 & 0.5 & & & & & & & \\
\hline \multicolumn{10}{|l|}{ Medicine and Rheumatology } \\
\hline Bronchial asthma & 3.2 & 0.6 & A & Between & 22.5 & 3 & 7.5 & \multirow[t]{4}{*}{33.0} & \multirow[t]{4}{*}{0.000} \\
\hline COPD & 3.4 & 0.6 & \multirow{3}{*}{$\begin{array}{l}\mathrm{N} \\
\mathrm{O} \\
\mathrm{V} \\
\mathrm{A}\end{array}$} & Within & 45.2 & 199 & \multirow[t]{3}{*}{0.2} & & \\
\hline Kala-azar & 3.9 & 0.3 & & Total & 67.7 & 202 & & & \\
\hline Rheumatoid arthritis & 4.0 & 0 & & & & & & & \\
\hline
\end{tabular}

\section{Discussion}

Though clinical decisions are based on scientific medical knowledge, a large gap remains between our knowledge and practice (Sackett et al., 1996). In spite of efforts to improve guideline adherence, success was very little due to different barriers (Lugtenberg et al., 2011).

The present study revealed that two-third of the key prescribers of BSMMU hospital was aware about treatment guidelines, though that varied in different departments. The observed level of awareness is slightly higher than the American licensed pediatricians (Christakis and Rivara, 1998), which indicate similar learning attitude of the physicians working both in rich and poor countries.

This study revealed very poor adherence in case of pediatric patients, i.e., only one-fourth. Non-adherence was mainly due to incorrect dose calculation and use of unmentioned medicine. Of the treated diseases, the adherence was highest in neonatal sepsis, i.e., 71.7 percent, where a protocol was adopted by the department and that consensus among potential prescribers perhaps contributed positively. The adherence was lowest, i.e., 3.3 percent in case of bronchial asthma, where the gold standard was the National Guideline. Australian (Sanders et al., 2002) and American (Rastogi et al., 2006) studies revealed high adherence in case of bronchial asthma, moreover the US investigators have identified negative influence of use of cough suppressants and salbutamol suspension. The very poor adherence in the present study perhaps negatively influenced by prescribing antimicrobials without documented evidence of required criteria, inappropriate selection, prescribing medicine discouraged like salbutamol and antihistamine. One-third of the brochiolitis cases adhered with the National Guideline, which is because of prescribing antimicrobials in response to suspicion of pneumonia and bacterial co-infections without documented evi- 
dence as well as prescribing of other discouraged medicine. In child-hood pneumonia in 7-24 months or above age group, incorrect medicine selection was the principal deviation. Whereas, in 0-6 months age group, incorrect dose calculation was the main contributor for non-adherence. This is further worsened by the fact that recommended dosing of the National Guideline does not correspond with that of Bangladesh National Formulary.

The present study revealed that in adult patients more than half, i.e., 54.8 percent of the prescription adhered with the guideline. The adherence was highest, i.e., 100 percent in rheumatoid arthritis and lowest, i.e., 13.3 percent in bronchial asthma. Highest adherence in rheumatoid arthritis was perhaps because the most potential area of deviation, biological medicines were not prescribed by the key prescribers of Department of Rheumatology due to financial considerations and other social issues. Moreover, the recommendations of NICE guideline on selection of medicine were flexible mentioning clinical judgment of the prescribers, which provided adequate flexibility that contributed positively on adherence. Motivation and social awareness kept the prescribers away from the deviation. Adherence was low, i.e., 13.3 percent in bronchial asthma, which was due to antimicrobial and anti-histamine prescribing without documented required criteria as well as use of theophylline in some cases. There was also some reluctance on the part of residents regarding dose calculation and frequency of administration. Though adherence was little higher than asthma, i.e., 31.7 percent in case of COPD, the influencing factors possibly were similar. Most of the kala-azar, i.e., 87.0 percent patients adhered to the National guideline, the remaining non-adherence was due to little reluctance during rounding up of the calculated dose.

Adherence rate is more in case of international guideline followed by institutional guideline, i.e., consensus protocol and lowest with National guideline. This feature reflects the better acceptance of International guideline by the prescribers of BSMMU than that of the institutional and national. The higher acceptance of national guideline for kala-azar was perhaps because of absence of alternative therapy.

The present study revealed variation in adherence in pediatric and adult patients, which perhaps mainly because of difference in disease, structure of guidelines and issue of individual dose calculation.

Audit and feedback has been used as a strategy for improving clinical practice behaviors (Hysong et al., 2006), as well as cost-effectiveness of the prescriptions (Islam et al., 2007). Therefore, well structured 'audit and feedback' of the observations of the present study might have some positive impact on the adherence status.
From the in-depth interview, the key prescribers have identified some managerial deficiencies like improper distribution, inadequate persuasion and communication gap as the reasons for non-adherence. Prescriber also mentioned some scientific defects like faulty development procedure, too rigid to cope with the difference in clinical response and guidelines are also too complicated. These are quite similar with that of the American pediatricians, who criticized their guideline as 'too cookbook,' 'too time consuming' and 'too cumbersome' (Christakis and Rivara, 1998). In addition, the prescribers noticed some lack of motivation, reluctance on the side of young residents and time constraint to comply with the documentation requirements of the guideline. In order to improve, changes at different levels of medical education, particularly in teaching and evaluation system of pharmacology (Rahman, 1995), might be effective.

The present study revealed that though a high proportion of prescriber know about the guideline, but they follow the guideline to limited extent, which reiterated the gap between prescriber's knowledge and practice (Sackett et al., 1996). The suggestions of the prescribers in order to improve adherence corresponds with the previous recommendations from Netherland (Lugtenberg et al., 2011; Mistiaen et al., 2012) and USA (Cohn et al., 2008).

There is a significant variation in extent of adherence in different diseases treated by prescribers of BSMMU Hospital. The findings of the present study might be helpful for better designing of subsequent institutional and national treatment guidelines as well as enforcement of guidelines in other institutions of Bangladesh.

\section{References}

Arhinful DK, Das AM, Hadiyono JP, Heggenhougen K, Higginbotham N, Iyun FB, Quick J, Degnan DR. How to use applied qualitative methods to design drug use interventions. Massachusetts, USA, INRUD social scientist working group, 1996.

Bangabandhu Sheikh Mujib Medical University (BSMMU). Antibiotic guideline. Dhaka, 2005.

Bangabandhu Sheikh Mujib Medical University (BSMMU). Guideline for the treatment of genitourinary cancer. Dhaka, 2012.

Brook RH. Practice guidelines and practicing medicine: Are they compatible? JAMA. 1989; 262: 3027-30.

Brown EM. Guidelines for antibiotic uses in hospitals. J Antimicrob Chemo. 2002; 49: 587-92.

Chowdhury AK, Rahman MS, Faroque AB, Hasan GA, Raihan $\mathrm{SZ}$. Excessive use of avoidable therapeutic injections in the upazilla health complexes of Bangladesh. Mym Med J. 2008; 17(2 Suppl): S59-64.

Christakis DA, Rivara FP. Pediatricians' awareness of and 
attitudes about four clinical practice guidelines. Pediatrics 1998; 101: 825-30.

Cohn JN. Monitoring adherence to guidelines. Circulation: Heart Failure 2008; 1: 87-88.

Das AK, Rahman MS. Prescribing vitamins at primary health care level: Exploration of facts, factors and solution. Bangladesh J Pharmacol. 2010; 5: 92-97.

Director General of Health Services (DGHS). Health Bulletin, 2012.

Directorate of Drug Administration (DDA). Bangladesh Medical Association (BMA), Bangladesh Pharmaceutical Society (BPS). Bangladesh National Formulary. 3rd ed. Dhaka, 2006.

Field MJ, Lohr KN, (eds). Clinical practice guidelines: Directions for a new program. Washington DC, National Academy Press, 1990.

Grill R, Margini N, Penna A. Practice guidelines developed by specialty societies: The need for a critical appraisal. Lancet 2000; 355: 103-06.

Grimshaw JM, Russell IT. Achieving health gain through clinical guidelines: Ensuring guidelines change medical practice. Qual Health Care. 1994; 3: 45-52.

Haque MM. ABC of research methodology and biostatistics. Department of Biochemistry, BSMMU, Dhaka, 2009.

Hogerzeil HV. Field tests for rational drug use in twelve developing countries. Lancet 1993; 342: 1408-10.

Hogerzeil HV. Promoting rational prescribing: An international perspective. Br J Clin Pharmacol. 1995; 39: 1-6.

Hysong SJ, Best RG, Pugh JA. Audit and feedback and clinical practice guideline adherence: Making feedback actionable. Impl Sci. 2006; 1: 9.

Islam MS, Rahman MS, Misbahuddin M. Impact of 'Prescription audit \& feedback' on pattern of prophylactic antimicrobials in caesarean section: A cost reduction perspective. Bangladesh J Physiol Pharmacol. 2007; 23: 1-9.

Kafuko JM, Zirabumuzaale C, Bagenda D. Rational drug use in rural health units of Uganda: Effect of National Standard Treatment guidelines on rational drug use, 1994: (Unpublished report)

Lugtenberg M, Burgers JS, Besters CF, Han D, Westert GP. Perceived barriers to guideline adherence: A survey among general practitioners. BMC Fam Prac. 2011; 12: 98.

Mistiaen P, Bloemendal E, Weenink J, Harmsen M. Guideline adherence in the Netherlands: A systematic review, 2012;

Nabiswa AK, Makokha JD, Godfrey RC, Lore W. Management of malaria before and after introduction of a treatment protocol at the Eldoret District Hospital. East Afr Med J. 1994; 71: 9-13.

Naivalulevu L. Training for rational drug use. ARI News 1990; 18 November: 5 .

Quick JD, Laing RO, Ross-Degnan DG. Intervention research to promote clinically effective and economically efficient use of pharmaceuticals: the International network for Rational Use of drugs. J Clin Epid. 1991; 44: 57-65.

Rahman MS, Akhter N, Haque MZ, Begum M, Chowdhury FA, Karim A, Khan IA. Prescribing pattern of Antimicrobials at different level of health care services and the impact of interventions (unpublished report).

Rahman MS, Begum M, Hoque MZ, Akhter N. Drug advertisements in medical journals: A commentary. Bangladesh J Physiol Pharmacol. 1999; 15: 31-36.

Rahman MS, Begum M, Khan IA, Chowdhury S, Islam AMZ, Sultana R, Hoque MZ, Akhter N. A baseline survey on the use of drugs at private practitioner level in Bangladesh. Bangladesh J Physiol Pharmacol. 1998; 14: 47-50.

Rahman MS. Changes required in pharmacotherapy teaching to ensure rational use of drugs. Bangladesh J Physiol Pharmacol. 1995; 11: 38-39.

Rastogi D, Shetty A, Neugebauer R, Harijith A. National Heart, Lung, and Blood Institute guidelines and asthma management practices among inner-city pediatric primary care providers. Chest 2006; 129: 619-23.

Sackett DL, Rosenberg WMC, Gray JAM, Haynes RB, Scott W. Evidence based medicine: What it is and what it isn't. Br Med J. 1996; 312: 71-72.

Sanders TR, Roberts CL, Gilbert GL. Compliance with a protocol for intrapartum antibiotic prophylaxis against neonatal group B streptococcal sepsis in women with clinical risk factors. Infect Dis Obs Gyn. 2002; 10: 223-29.

Siddika AN. Does antimicrobial prescribing of BSMMU Hospital comply to its' antibiotic guideline? Thesis, (MPhill). Bangabandhu Sheikh Mujib Medical University, Dhaka, 2012.

World Health Organization (WHO). How to investigate drug use in health facilities: Selected drug use indicators. Geneva, World Health Organization, 1993. 